\title{
The Built Environment and Transport-Related Physical Activity: What We Do and Do Not Know
}

\author{
Hannah M. Badland and Grant M. Schofield
}

\begin{abstract}
Background: Leisure time physical activities have been a priority in recent years for many health practitioners, with transport-related physical activity (TPA) largely ignored. The urban environment has altered in the last few decades, increasing the reliance on automobiles. Simultaneously we have seen increases in obesity and other non-communicable diseases related to sedentary lifestyles. Methods: Information was sourced from major health databases. The remainder of the literature was directed from citations in articles accessed from the initial search. Results: Clear health benefits result from regular TPA engagement, with opportunities closely linked to accessible urban design infrastructure. Much of the existing evidence, however, has been extracted from cross-sectional research, rather than interventions. As such, drawing causal relationships is not yet possible. Conclusions: Existing evidence necessitates TPA research and promotion should be public health and urban design priorities. Collaborative research needs to incorporate prospective study designs to understand TPA behavior.
\end{abstract}

Key Words: urban design, transport, physical activity

\section{The Case for Transport-Related Physical Activity}

Vehicle congestion, traffic accidents, and pedestrian fatalities have been the primary concerns for urban designers and transport researchers for many decades, ${ }^{1}$ whereas public health officials have examined the relationship between the built environment and health status, namely respiratory health, ${ }^{2}$ cardiovascular disease,${ }^{3}$, ${ }^{4}$ and social capital. ${ }^{5}$ Although these problems are worthy of attention, the burden of disease and subsequent mortality rate from physical inactivity is alarmingly high, ${ }^{6,7}$ and health practitioners are becoming increasingly concerned at the low physical activity levels within developed and developing countries, and resulting co-morbidities. ${ }^{6}$ It is estimated that non-communicable diseases account for $60 \%$ of all deaths, and $47 \%$ of global burden of disease. These figures are expected to rise to $73 \%$ and $60 \%$, respectively, by $2020,{ }^{8}$ in part because of the changing environment that supports sedentary lifestyles. ${ }^{9}$ Increasingly, evidence is linking

The authors are with the Centre for Physical Activity and Nutrition Research, Faculty of Health and Environmental Sciences, Auckland University of Technology, Auckland 1020, New Zealand. 
community design and the built environment to physical activity levels. Several recent comprehensive reviews ${ }^{10,11,12,13}$ have identified aspects of urban design associated with activity behaviors. Following on from these, two inclusive reviews have specifically documented correlates of transport-related physical activity (TPA), both from health ${ }^{14}$ and urban design ${ }^{15}$ perspectives. The latter reviews pointedly demonstrate that TPA should become a public health priority, with the Task Force on Community Preventive Services ${ }^{16}$ and the World Health Organization ${ }^{8}$ further recommending environmental and policy approaches to increase physical activity levels. Accordingly, the US national health surveillance survey (Behavioral Risk Factor Surveillance Systems [BRFSS]) has been incorporating transport-related questions from 2001 onwards ${ }^{17}$ Although this is a worthy initiative, the current BRFSS survey cannot track TPA as the frequency and duration are not recorded independent to leisure time physical activity (LTPA). Despite this, the present review strengthens the case for focusing on TPA behavior by addressing pertinent urban design variables, travel behavior, and associated health outcomes.

\section{Current Transport Trends}

Industrialized countries are becoming increasingly reliant on automotive travel. As cities become more sprawling and less connected, few realistic alternatives other than private automobile use are available. ${ }^{1,18}$ Motorized travel now replaces many TPA journeys, existing as the main form of transport in many industrialized countries, ${ }^{19}$ and ownership is increasing rapidly in developing nations, such as China. ${ }^{20}$ Despite this trend, preliminary findings from the Strategies for Metropolitan Atlanta's Regional Transportation and Air Quality (SMARTRAQ) survey detailed $40 \%$ of all current motorized trips in the area could reasonably be substituted with TPA travel. The survey reasoned replaceable journeys were for food, school transport, shopping, and entertainment. ${ }^{21}$ Indeed, the World Health Organization suggests that transport policies should focus on promoting walking and cycling for trip distances less than $5 \mathrm{~km} .{ }^{8}$ Although non-motorized travel occurrences are reducing, ${ }^{22}$ TPA promotion might be a realistic approach to accumulate physical activity, largely because of the combined and vested interest from transport and health sectors. Government organizations in industrialized countries are now beginning to understand the economic, social, and health impacts of automotive dependency. ${ }^{23}$ TPA offers promise as a sustainable option, as it fulfils the dual purpose of physical activity and transport, while becoming a habitual transportation mode. Aside from being readily accessible for the majority of the population, cycling and walking are multifunctional modes of TPA, incorporating substantial health and transport benefits while causing no pollution. Each mode is cost efficient, both from an energy and infrastructure viewpoint when compared to relative automobile costs, ${ }^{8}$ and is complementary to other travel modes. This is evident in transit, where a review using data sourced from the Netherlands, Germany, and the United Kingdom, indicated people would cycle up to $5 \mathrm{~km}$ to access transit facilities. ${ }^{24}$ The acceptance of non-motorized travel as an acceptable transport mode varies by country, and is particularly evident when comparing travel-related cycling levels between non-European and northern European industrialized nations. ${ }^{22,24,25}$ Travel differences also exist between first world countries and developing nations. In 
China, $94 \%$ of adults regularly commuted to work via physical activity, ${ }^{26}$ whereas $8 \%$ of United States adults perceived that it was unreasonable to walk for transport at all, and $45 \%$ would only walk between 0.25 and 1 mile for TPA. ${ }^{17}$ Similarly, only $7 \%$ of Australians walked regularly for transport. ${ }^{27}$ Those that had irregular or no access to an automobile were significantly more likely to walk for TPA. ${ }^{28}$ Despite these findings, no comparative physical activity data were taken between TPA and LTPA engagers, and to our knowledge, no research has investigated physical activity differences between TPA and LTPA behaviors. Aside from a paucity of comparative data, TPA research has not been a focus for public health or transport researchers. There are several reasons for this. First, TPA modes are viewed as low-technical investments, which make up only a modest share in total traffic. ${ }^{1}$ Second, as with any physical activity intervention, the individual exertion required might deter participants. Although this could be the case, the potentially shorter distances associated with commuting and participating in purposive activity, in conjunction with self-selected intensity, could act as incentives to engage in the behavior. Third, measurement issues are associated with TPA. Trips might be hard to measure, partly because they can exist as part of a trip-chain. Lastly, TPA behavior is dependent on existing localized built environment infrastructure and destination access. Although only limited non-motorized travel studies exist, ${ }^{14}$ urban planners are acknowledging the importance of TPA as a means to reduce traffic congestion and pollution when traveling short distances, ${ }^{23,29}$ while physical activity practitioners' view the behavior as a mechanism to increase habitual activity and improve population health outcomes.

\section{Transport-Related Physical Activity and Health}

Aside from improving the cost-benefit ratio of travel, TPA could provide comparable health benefits when weighed against LTPA. Potential reasons include accumulation of small, regular doses of physical activity with individuals using TPA as a form of transport for traveling to and from destinations, doubling the physical activity exposure. Documented health outcomes associated with TPA include reduced bodymass index (BMI), ${ }^{30}$ improved blood lipid profile, ${ }^{31,32}$ lowered hypertension, ${ }^{26,33}$ and all-cause mortality ${ }^{34}$ in a variety of different populations. Indeed, those who partake in TPA often report little or no LTPA, but often convey superior health statuses when compared LTPA engagers. For example, men who actively commuted to work showed a weight reduction $(r=-0.0075, P=0.07)$, whereas those who only engaged in moderate intensity LTPA detailed no significant body mass diminutions ( $r=-0.0564, P=0.70$ ). On a cautionary note, no incremental correlations were presented regarding TPA intensity and duration with body mass. ${ }^{30} \mathrm{~A}$ more recent study detailed Chinese adults who recorded the lowest blood pressure, engaged daily in 31 to 60 min of TPA, or TPA combined with LTPA, and men who completed 1 to $30 \mathrm{~min}$ of TPA daily were less likely to be overweight $(\mathrm{OR}=0.70 ; 95 \% \mathrm{CI}=$ 0.49 to 0.99$)$ than those who engaged in the same duration of LTPA $(\mathrm{OR}=0.89$; $95 \% \mathrm{CI}=0.70$ to 1.13$).{ }^{26}$ Another study $(N=3708)$ reported significant inverse associations with serum lipids and TPA, but not with LTPA. ${ }^{32}$ A prospective study has also demonstrated reduced all-cause mortality for those who cycled to work $(\mathrm{RR}=0.72 ; 95 \% \mathrm{CI}=0.57$ to 0.91$)$, even after controlling for LTPA, BMI, blood 
lipid profile, smoking, and blood pressure. ${ }^{34}$ A caveat of these findings, however, are that some potential confounders, such as activity frequency and duration, and total energy expenditure, were not controlled for in the aforementioned studies.

\section{Correlational Studies}

Walking has been associated with health benefits. ${ }^{6}$ A Japanese study tracked men $(N$ $=6017$ ) in sedentary occupations for 59,784 person-years. Those who walked for 11 to $20 \mathrm{~min}(\mathrm{RR}=0.88 ; 95 \% \mathrm{CI}=0.75$ to 1.04$)$ and $\geq 21 \mathrm{~min}(\mathrm{RR}=0.71 ; 95 \%$ $\mathrm{CI}=0.52$ to 0.97 ) to work had a reduced relative risk of developing hypertension ( $\geq 160 / 95 \mathrm{~mm} \mathrm{Hg}$ ). In practical terms, 1 case of hypertension was prevented for every 26.3 men who walked more than 20 min to work. No significant relationship was evident between LTPA and TPA. ${ }^{33}$ This relationship, however, might be different for children. Using accelerometers as a criterion measure, those who walked to school accumulated significantly more step counts/min $(712.0 \pm 206.7)$ than children who were driven to school $(629.9 \pm 207.2)$. Boys who engaged in TPA were also more active after school and in the evening than boys who commuted by car. This relationship was not evident in girls. ${ }^{35}$ As well as showing associations with chronic diseases and overall activity accumulation, an inverse relationship has been demonstrated between TPA and weight. Adults who habitually expended at least $10 \mathrm{MET} \mathrm{h} / \mathrm{wk}$ actively commuting to work, but did not necessarily report vigorous exercise, demonstrated a reduction in body mass. ${ }^{30}$ Consequently, researchers are now trying to ascertain a relationship between physical activity, obesity, and the built environment. This association is being addressed in the SMARTRAQ study. The multi-disciplinary study is the first to establish BMI and physical activity patterns within a household travel survey. Preliminary data show significant relationships with lower obesity rates with more compact, dense, mixed use, and transit-accessible neighborhoods and decreased time spent in an automobile and kilometers walked. ${ }^{21}$ Other research documented Chinese people who own automobiles were $80 \%(P$ $<0.05)$ more likely to be obese than individuals who did not. Men who acquired an automobile over an 8 -y time period, on average, were also $1.8 \mathrm{~kg}$ heavier $(P<$ $0.05)$ than those who only had access to non-motorized transport. Chinese women reported a $0.4 \mathrm{~kg}$ increase also, but the relationship was not significant once adjusted for confounders. ${ }^{20}$

\section{Intervention Studies}

TPA interventions have proved difficult to implement, largely because the success of the study is dependent on local urban infrastructure and individual adherence. ${ }^{14}$ To our knowledge, no interventions to increase local shopping TPA exist, and only two TPA worksite commuting studies have been identified in the literature. ${ }^{31,36} \mathrm{~A}$ 10 -wk Finnish intervention to increase TPA levels $(N=68)$ for inactive employees yielded encouraging findings. Post mean walking and cycling trip distances were $3.4 \mathrm{~km}$ and $9.7 \mathrm{~km}$, respectively, and approximately $85 \%$ of participants commuted to and from the workplace via TPA daily. No post-intervention adherence data were obtained, however. Positive physiological changes included improved blood lipid profiles, $\mathrm{VO}_{2 \max }$, heart rate, and blood lactate. ${ }^{31}$ Mutrie et al. ${ }^{36}$ conducted a randomized controlled trial using the transtheoretical model of behavior change to encourage walking to and from work $(N=295)$. At the conclusion, the intervention 
group increased walking to work more than the control $(\mathrm{OR}=1.93 ; 95 \% \mathrm{CI}=1.06$ to 3.52 ). A promising finding was that $25 \%$ of the initial inactive intervention group remained physically active 1 y post-intervention. ${ }^{36}$ To summarize, despite the lack of intervention data, existing evidence clearly demonstrates TPA is a viable tool to improve population health outcomes. Numerous cross-sectional studies show the importance of TPA as a valuable way to accumulate physical activity and the limited intervention studies show promise. Despite these benefits, it is imperative that we understand travel behavior before developing TPA interventions.

\section{Travel Behavior}

To promote TPA modes, it is necessary to understand why and how individuals choose travel. TPA might not be primarily engaged in for health benefits, but instead reflect convenience, time, and other urban design factors relative to other travel modes. Based on this premise, individuals could tend to engage in whichever transport mode will be the most convenient to access destinations, and it is likely that time constraints and expediency might be influential in this contemporaneous environment. Urban designers, rather than public health practitioners, could have the greatest influence on TPA travel. Practically, to increase TPA levels in the built environment, urban design convenience factors, such as street design, residential and employment density, and mixed land use, need to be maximized to enhance the utility of TPA, making it a realistic alternative to other modes.

\section{Transport, Urban Design, and Physical Activity}

Evidence supports that built environment modifications are a logical way to influence population-level behavior. For individuals to realistically engage in TPA, the environment needs to support convenient and efficient travel through urban design fundamentals. The association between the built environment and physical activity has long been recognized, ${ }^{37}$ however, the collaboration of transport, urban planning, and health professionals is a relatively new phenomenon. ${ }^{14,15}$ Pertinent urban design variables are discussed in greater detail below.

\section{Street Design}

Post-World War II, suburbanization commenced resulting in incorporation of unconnected street networks (cul-de-sacs) and reduced number of intersections, thereby replacing the finer-grained traditional grid design. ${ }^{22}$ This increases the network distance to destinations and often makes non-motorized travel unrealistic. Accordingly, almost three times as much TPA activity occurs within urban settings, largely because of reduced connectivity within suburban neighborhoods. ${ }^{38}$ For example, in the San Francisco Bay area, twice as many non-motorized trips were taken by TPA in the urban setting (19\% versus $10 \%)$, and automobile use was $32 \%$ higher in suburban areas. ${ }^{39}$ This reinforces the underlying assumption that finer neighborhood grains increase TPA travel. ${ }^{41}$ Street design extends to cycling and walking paths. Well-connected bicycle networks exist in many northern European countries, providing practical links to destinations. ${ }^{25}$ The high ratio of separate scenic cycling corridors in non-European industrialized countries, however, indi- 
cates that the behavior has not become integrated in the transport system. ${ }^{42}$ This has been reiterated at an international conference where cycling was viewed as a recreational activity, and its acceptance as a commuter vehicle in daily use was missing in many Westernized countries. ${ }^{43}$ Despite this, a positive relationship exists between miles of bicycle pathways and percentage of cycle commuters in the US. ${ }^{44}$ States that detailed higher cycle commuting levels reported more miles of cycle pathways leading to specific destinations.

\section{Density}

The critical mass of population density influences transport in various ways. Highdensity areas have greater concentrations of trip-ends, thereby lessening trip length and distances through minimizing travel outside the localized area. ${ }^{45}$ Substantial population density also ensures transit is financially feasible. ${ }^{40}$ US cities typically have low density (14 people/hectare) and use buses and trains for $8 \%$ of travel, whereas Asian cities have 168 residents per hectare and utilize those transport modes for $30 \%$ of all trips. ${ }^{46}$ Moreover, higher densities increase traffic congestion and make car parking prohibitive by increasing cost and restricting accessibility. ${ }^{47}$ Density also shows an exponential association to TPA and transit, ${ }^{48,49}$ and an inverse relationship with vehicle ownership, ${ }^{50}$ and commuting use.$^{51}$ Specifically, employees with one automobile per household were more likely to use it for commuting purposes if they lived in a low-density neighborhood $(r=0.78)$ versus an area with medium to high densification $(r=0.29) .^{51}$

\section{Mixed Land Use}

Mixing residential and commercial properties within a localized area reduces distances to facilities, thereby increasing the perception of convenience. ${ }^{51}$ Residents in high mixed use areas reported more time walking for errands than those residing in neighborhoods with limited mix land use, ${ }^{52,53}$ and living within walking distances of shops $(P<0.01)$ has also been positively associated with higher pedometer step counts. ${ }^{54}$ Handy and Clifton ${ }^{55}$ examined mixed land use and TPA in 6 neighborhoods. Traditional neighborhoods (pre-1950) averaged 215 stores within a 0.5 mile radius compared to 48 shops for the late modern areas (post-1970). Typically, 50\% of trips to the shops from the traditional localities were walked, in comparison to $3 \%$ in the late modern neighborhoods. ${ }^{55}$

As well as engaging in more TPA, those who live in neighborhoods with increased land use mix are at reduced risk of being overweight or obese. ${ }^{21}$ Frank et al. ${ }^{21}$ detailed that for each quartile increase in land mix, there was a reduced likelihood $(12.2 \%)$ of residents being classified as obese $(\mathrm{OR}=0.88 ; 95 \% \mathrm{CI}=0.84$ to 0.92). The study did not show a significant relationship between weight status and density. Cervero ${ }^{51}$ also detailed that the presence of local shops might operate as a better predictor of TPA engagement than population density.

\section{Modal Choice}

Choosing travel modes appears to be based on a complex relationship of sociodemographic characteristics and localized urban design. Transit use is primarily a product of trip destination density, mixed land use, and density. Specifically, 
previous research has shown residents in traditional neighborhoods were more likely to carpool (9\% versus $7 \%$, respectively), engage in transit and TPA modes (19\% versus $10 \%$, respectively), and were less likely to travel to work from home by an automobile ( $69 \%$ versus $83 \%$, respectively) when compared to residents of suburban neighborhoods. ${ }^{39}$ Another study also reported a similar relationship with use of public transport. After controlling for confounders, those living in higher density, increased mixed land use neighborhoods reported increased use of rail stations for work purposes. A positive relationship was also evident with transit use and size of employment center. ${ }^{56}$

\section{Future Directions}

Although substantial health benefits from TPA exist, there are many areas that require further research. Currently, much of the research is directed towards understanding how the built environment influences general physical activity. Future TPA initiatives should aim to identify locality and demographic differences, perceptions, environmental barriers, and trip origin and destination information. Comparisons of those who do and do not engage in TPA could also help to understand non-motorized travel by revealing key components of the behavior. Valid and reliable TPA measuring and tracking tools, such as questionnaires, accelerometers, and geographic information systems, need to be developed and incorporated into existing regular surveys to ascertain population level TPA data and health outcomes. Further work also needs to separate TPA from total activity before prospective study designs can be implemented. As such, much work remains to be conducted before TPA can be understood comprehensively.

\section{Acknowledgments}

The first author acknowledges the support of the New Zealand National Heart Foundation through the Maori Cardiovascular Research Fellowship, and the Maurice and Phyllis Paykel Scholarship in Health Sciences. The authors are also grateful to the reviewers who provided comprehensive feedback on the manuscript submissions.

\section{References}

1. Litman, T. Integrating public health objectives in transportation decision-making. Am J Health Promotion. 2003;18:103-108.

2. Kunzli N, McConnell R, Bates D, Bastain T, Hricko A, Lurmann F, Avol E, Gilliand F, Peters J. Breathless in Los Angeles: The exhausting search for clean air. Am J Public Health. 2003;93:1494-1499.

3. Hoek G, Brunekreef B, Goldbohm S, Fischer P, van den Brandt P. Association between mortality and indicators of traffic-related air pollution in the Netherlands: A cohort study. Lancet. 2002;360:1203-1209.

4. Peters A., von Klot S, Heier M, Trentinaglia I, Hörmann A, Wichmann H, Löwel H. Exposure to traffic and the onset of myocardial infarction. $N$ Engl J Med. 2004;351: 1721-1730.

5. Kawachi I, Kennedy BP, Glass R. Social capital and self-rated health: A contextual analysis. Am J Public Health. 1999;89:1187-1193.

6. Dept of Health, Physical Activity, Health Improvement and Promotion. At least five a 
week: Evidence from the impact of physical activity and its relationship to health. $A$ report from the Chief Medical Officer. 2004; Dept of Health, London.

7. Pruss-Ustan A, Mathers C, Corvalan C, Woodward A J. Introduction and methods: Assessing the environmental burden of disease at national and local levels. World Health Organization. 2003; Geneva.

8. World Health Organization. Global strategy on diet, physical activity and health. World Health Organization. 2003; Geneva.

9. Saris WHM, Blair SN, van Baak MA, Eaton SB, Davies PSW, Di Pietro L, Fogelholm M, Rissanen A, Schoeller D, Swinburn B, Tremblay A, Westerterp KR, Wyatt HR. How much physical activity is enough to prevent unhealthy weight gain? Outcome of the IASO 1st Stock Conference and consensus statement. Obes Rev. 2003;4:110-114.

10. Humpel N, Owen N, Leslie E. Environmental factors associated with adults' participation in physical activity. Am J Prev Med. 2002; 22:188-199.

11. McCormack G, Giles-Corti B, Lange A, Smith T, Martin K, Pikora T. An update of recent evidence of the relationship between objective and self-report measures of the physical environment and physical activity behaviours. J Sci Med Sport. 2004;7:8192.

12. Owen N, Humpel N, Leslie E, Bauman A, Sallis JF. Understanding environmental influences on walking; review and research agenda. Am J Prev Med. 2004; 27:67-76.

13. Owen N, Leslie E, Salmon J, Fotheringham MJ. Environmental determinants of physical activity and sedentary behavior. Exerc Sports Sci Rev. 2000;28:153-158.

14. Sallis JF, Frank LD, Saelens BE, Kraft MK. Active transportation and physical activity: Opportunities for collaboration on transportation and public health research. Transportation Research Part A: Policy and Practice. 2004;38:249-268.

15. Saelens BE, Sallis JF, Frank LD. Environmental correlates of walking and cycling: findings from the transportation, urban design, and planning literatures. Ann Behav Med. 2003;25:80-91.

16. Kahn EB, Ramsey LT, Brownson RC, Heath GW, Howze E, Powell KE, Stone EJ, Rajah MW, Corso P. Task Force on Community Preventive Services. The effectiveness of interventions to increase physical activity: A systematic review. Am J Prev Med. 2002;22:S73-S107.

17. Rafferty AP, McGee HB, Petersmarck KA, Miller CE. Proportion of trips made by walking: Estimating a state-level baseline for Healthy People 2010 objective 22-14. Am J Health Promotion. 2004;18:387-391.

18. Corburn J. Confronting the challenges in reconnecting urban planning and public health. Am J Public Health. 2004; 94:541-546.

19. Land Transport Safety Authority (2000) Land Transport Safety Authority, Wellington, New Zealand.

20. Bell AC, Ge K, Popkin BM. The road to obesity or the path to prevention: Motorized transportation and obesity in China. Obes Res. 2002;10:277-283.

21. Frank LD, Andresen MA, Schmid TL. Obesity relationships with community design, physical activity, and time spent in cars. Am J Prev Med. 2004; 27:87-96.

22. Frank LD, Engelke PO, Schmid TL. Health and community design: The impact of the built environment on physical activity. Washington, DC: Island Press; 2003.

23. Killingsworth RE, Schmid TL. Community design and transport policies: New ways to promote physical activity. Phys Sportsmed. 2001;29:1-4.

24. Martens K. The bicycle as a feedering mode: Experiences from three European countries. Transportation Research Part D: Transport and Environ. 2004;9:281-294.

25. Pucher J, Dijkstra L. Promoting safe walking and cycling to improve public health: Lessons from Netherlands and Germany. Am J Public Health. 2003;93:1509-1516.

26. Hu G, Pekkarinen H, Hanninen O, Yu Z, Guo Z, Tian H. Commuting, leisure-time physical activity, and cardiovascular risk factors in China. Med Sci Sports Exerc. 2002;34: 234-238. 
27. Giles-Corti B, Donovan R. Relative influences of individual, social environmental, and physical environmental correlates of walking. Am J Public Health. 2003;93:15831589.

28. Giles-Corti B, Donovan RJ. Socioeconomic status differences in recreational physical activity levels and real and perceived access to a supportive physical environment. Prev Med. 2002;35:601-611.

29. Handy SL, Boarnet MG, Ewing R, Killingsworth R. How the built environment affects physical activity: Views from urban planning. Am J Prev Med. 2002;23:64-73.

30. Wagner A, Simon C, Ducimetiere P, Montaye M, Bongard V, Yarnell J, Bingham A, Hedelin G, Amouyel P, Ferrieres J, Arveiler D. Leisure-time physical activity and regular walking or cycling to work are associated with adiposity and 5y weight gain in middle-aged men: The PRIME study. Int J Obes. 2001;25:940-948.

31. Vuori IM, Oja P, Paronen O. Physically active commuting to work: Testing its potential for exercise promotion. Med Sci Sports Exerc. 1994;26:844-850.

32. Hu G, Pekkarinen H, Hanninen O, Tian H, Guo Z. Relation between commuting, leisure time physical activity and serum lipids in a Chinese urban population. Ann Hum Biol. 2001;28:412-421.

33. Hayashi T, Tsumura K, Suematsu C, Okada K, Fujii S, Endo G. Walking to work and the risk for hypertension in men: The Osaka Health Survey. Ann Intern Med. 1999;130: 21-26.

34. Bo Anderson L, Schnohr P, Schroll M, Ole Hein H. All-cause mortality associated with physical activity during leisure time, work, sports, and cycling to work. Arch Intern Med. 2000;160:1621-1628.

35. Cooper AR, Page AS, Foster LJ, Qahwaji D. Commuting to school: are children who walk more physically active? Am J Prev Med. 2003;25:273-276.

36. Mutrie N, Carney C, Blamey A, Crawford F, Aitchison T, Whitelaw A. "Walk into Work Out": A randomized controlled trial of a self help intervention to promote active commuting. J Epidemiol Community Health. 2002;56:407-412.

37. Sallis JF, Hovell MF, Hofstetter CR, Faucher P, Elder JP, Blanchard J, Caspersen CJ, Powell KE, Christenson GM. A multivariate study of determinants of vigorous exercise in a community sample. Prev Med. 1989;18:20-34.

38. Moudon AV, Hess PM, Snyder MC, Stanilov K. Effects of site design on pedestrian travel in mixed-use, medium density environments. Transportation Res Rec. 1997;1578: 48-55.

39. Friedman B, Gordon S, Peers J. Effect of neotraditional neighborhood design on travel characteristics. Transportation Res Rec. 1994;1466:63-70.

40. Frank LD. Land use and transportation interaction: Implications on public health and quality of life. J Planning Educ Res. 2000;20:6-22.

41. Pucher J, Dijkstra L. Making walking and cycling safer: Lessons from Europe. Transportation Q. 2000;54:25-50.

42. Goldsmith SA. National bicycling and walking study. Case Study No 1: Reasons why bicycling and walking are and are not being used more extensively as travel modes. US Dept of Transportation, Washington, DC;1992.

43. Huwer U. Let's bike: The 10 Point Pedalling Action Programme to support cycling. World Transport Policy and Practice. 2000;6:40-44.

44. Nelson AC, Allen D. If you build them, commuters will use them. Transportation Res Rec. 1997;1578:79-83.

45. Ewing R, Cervero R. Travel and the built environment: A synthesis. Transportation Res Rec. 2001;1780:87-114.

46. Schafer A, Victor D. The future mobility of the world population. Transportation Res Part A: Policy and Practice. 2000; 34:171-205.

47. Pollard T. Policy prescriptions for healthier communities. Am J Health Promot. 2003;18: 109-113. 
48. Frank LD, Pivo G. Impacts of mixed use and density on utilization of three modes of travel: Single-occupant vehicle, transit, and walking. Transportation Res Rec. 1994;1466:44-52.

49. Cervero R. Land-use mixing and suburban mobility. Transportation Q. 1988;42:429446.

50. Holtzclaw JR Using residential patterns and transit to decrease auto dependence and costs. National Resources Defense Council, 1994; New York.

51. Cervero R. Mixed land-uses and commuting: Evidence from the American Housing Survey. Transport Research Part A: Policy and Practice. 1996;30:361-377.

52. Leslie E, Saelens BE, Frank LD, Owen N, Bauman AE, Coffee N, Hugo G. Residents' perceptions of walkability attributes in objectively different neighborhoods: A pilot study. Health \& Place. 2005;11:227-236.

53. Saelens BE, Sallis JF, Black JB, Chen D. Neighborhood-based differences in physical activity: An environment scale evaluation. Am J Public Health. 2003; 93:1552-1558.

54. King WC, Brach JS, Belle S, Killingsworth R, Fenton M, Kriska A. The relationship between convenience of destinations and walking levels in older women. Am J Health Promotion. 2003;18:74-82.

55. Handy SL, Clifton KJ. Local shopping as a strategy for reducing automobile travel. Transportation. 2001;28:317-346.

56. Cervero R, Radisch C. Travel choices in pedestrian versus automobile oriented neighborhoods. Transport Policy. 1996;3:127-141. 